\title{
Personal Observation of Parenteral Thiamin Therapy of Otorhinolaryngologic Disorders
}

\author{
Benjamin Yuehtung Lee ${ }^{1 *}$, Julia H Baí2, Zhengya $\mathrm{Li}^{3}$ and Yangrong Wang \\ ${ }^{1}$ Biochemical Genetics/Pediatrics, USA \\ ${ }^{2}$ Master Program of Epidemiology, USA \\ ${ }^{3}$ Uncle Ben's Clinic, China
}

ISSN 2637-7780

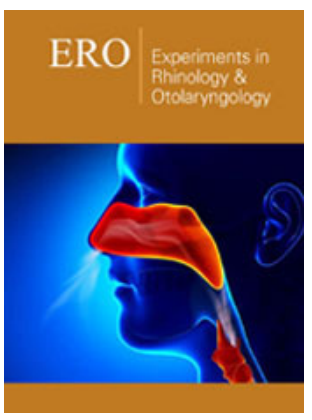

*Corresponding author: Benjamin Yuehtung Lee, Biochemical Genetics/ Pediatrics, USA

\section{Submission: 笽 May 25, 2019}

Published: 㑤June 13, 2019

Volume 3 - Issue 1

How to cite this article: Benjamin Yuehtung L, Julia H B, Zhengya L, Yangrong W. Personal Observation of Parenteral Thiamin Therapy of Otorhinolaryngologic Disorders. Exp Rhinol Otolaryngol 3(1). COJTS.000552.2019.

Copyright@ Benjamin Yuehtung Lee, This article is distributed under the terms of the Creative Commons Attribution 4.0 International License, which permits unrestricted use and redistribution provided that the original author and source are credited.

\begin{abstract}
This is a record of clinical phenomena observed among two kinds of patients: very hard laborers with inadequate food from a labor farm 1958-1962 and regular villagers from suburban area of a large city 1966-1977. After 2012, the author became a medical volunteer to help patients in those villages through international communication. In the farm, a lot of cases with severe, critical or fatal malnutrition were observed. Thiamin was found versatile in curing nearly all other B vitamins were also useful. These were preliminarily confirmed among the villagers. After 2012, the remotely experienced phenomena were successfully re-checked, including some ENT signs, symptoms, or syndromes such as nose catarrh drops and bleed, rhinitis, hypersecretion of ear wax, and vocal cord paralysis. The purpose of this paper is to introduce therapeutic effects of thiamin, riboflavin and niacin for these almost negligible ENT disorders.
\end{abstract}

Keywords: Catarrh; Ear wax hypersecreation; Epistaxia; Niacin; Rhinitis; Riboflavin Thiamin; Vocal cord paralysis

\section{Introduction}

The physiologic reactions of every system, organ, tissue or cell of human body depend on body energy, which is generated primarily from glucose in the food through a series of enzymatic procedures initiated with thiamin and magnesium. The domination importance of thiamin in nervous system, brain and heart had been well established [1]. While its function in peripheral tissue or cells is still in progress. In the following, a few inconspicuous ENT signs or disorders are described [2].

\section{Case Study}

\section{Senile catarrh}

The word catarrh or catarrhal often appears in art literature to describe a senior with dirty face full of watery or thicker discharges from the nose, especially in cold weather and the mealtime. This is also true in medical practice. Some aged often complain watery discharges dropping from the nose occasionally, intermittently or constantly. However, there is usually no obvious evidence of allergy, infection or trauma in the related mucous membrane inside the airway or cavity of the nose, sinuses, or throat. The problem might be due to cellular metabolic failure of local membrane although its structure might be normal. For example, body energy might be deprived in cases with thiamin over-consumption or under-supply as in the farm slavery laborers. The following is a civil example.

Li YD, 68, suffered from watery nose discharges for 2 years. In cold weather or at mealtime, he would have 30-50 clearly watery drops running out from nose within an hour about 5 seconds a drop. In a spring day, he became very fatigue and uncomfortable with poor sleep, when he got up, the catarrh drops became more about 2 second a drop and then progressed as a continuous thin stream. Thiamin $\mathrm{HCl} 300 \mathrm{mg}$ was injected. Immediately after injection, catarrh stream or drops disappeared without recurrence thereafter because he then took thiamin everyday regularly. In general, senile catarrh nasal drops in cold and mealtimes could be eliminated with parenteral B vitamins in large dose. This example indicated that catarrh might be resulted from thiamin deficiency in local membrane cells. Another important information is that within a few days after heavy nose catarrh, nosebleed might likely ensue if catarrh not corrected. 


\section{Rhinitis}

Acute or chronic running nose with massive yellowish mucus is commonly found in abused children or adults. Regular antibiotics are regularly used for a chronic course but often in vain. However, thiamin and riboflavin injections were dramatic to eliminate the dirty discharge, hypertrophy of inferior nasal concha, and breath difficulty. Massive mucous discharges disappeared usually within a week without recurrence. If associated with hypertrophy of inferior nasal concha, therapy for one month or more was required. In a case with severe chronic paranasal sinusitis to be operated, the surgery was avoided with parenteral thiamin $300 \mathrm{mg}$ twice a day for 12 days [3,4-6]. Another case, Mr Zhan XJ, 57, was diagnosed by the Tianjin First Central Hospital on Dec 17, 2018 (\#N712176286) to have coronary heart disease. He rejected stent setup but accepted parenteral thiamin $300 \mathrm{mg}$ once a day so as to keep his driving job. On his $50^{\text {th }}$ day of injection, a small and large piece of mucous "Clot" or booger was sneezed out and his rhinitis troubled him for several months finished and no recurrence [5].

\section{Nosebleed or epistaxia}

Nosebleed is not rare especially from the anterior source, Kiesselbach's plexus. It often involved the aged who were in uncomfortable status, such as severe fatigue, or poor sleep, especially after a few days with excessive catarrh drops from the nose. Although bleeding is very alarming, however, it could be stopped by pressing the bleeding nostril or inserting a small tissue roller and wait for 10-20 minutes for coagulation. If it was still refractory, intramuscular thiamin $\mathrm{HCl} 200-300 \mathrm{mg}$ would solve the problem immediately because the Klesselbach's plexus might be thiamin deficient causing micro-aneurysm and its rupture [4]. Nosebleed is often considered relating to hypertension. This is quite wrong because Klesselbach's plexus or Little's area might be very vulnerable to local deficiency of thiamin to develop microaneurysm as seen from terribly hard laborers with inadequate food over years.

\section{Hypersecretion of ear wax}

Ear wax is secreted from local sebaceous cells. We had meet troubles in a refractory case due to rare type of pellagra [3]. Patient was a 35-year old male and hospitalized for lobar pneumonia of 3 weeks, as a refractory consequence after severe lung infection, he suffered from excessive ear wax for the following 10 years. Each morning he would clean the outer ear canal with his finger or small ear spoon. The secretion would be a small piece of dry thin layer, a cheesy mass, or liquid sufficient to saturate several cotton swabs. Occasionally, he became deaf due to complete block of the outer ear canal with wax. Once upon a time, an area of $10 \mathrm{X} 20 \mathrm{~cm}$ on his pillow was contaminated with ear wax liquid during sleep. It should be noted that his pillow was not the regular one, but a wooden box covered with clothe. Regardless what form or material of his pillow was, the area of contamination, probably with $5-10 \mathrm{ml}$ of liquid ear wax, was large enough to cause medical attention. Local examination revealed slightly congestive tympanic membrane and excoriated ear canal. Cultures showed normal bacterial flora and no fungi. He had no skin lesion anywhere except for occasional moistness at the perineum. Oral and local antibiotics and local purging with hydrogen peroxide did not help. While he received thiamin $\mathrm{HCl}$ injections for leg pain, his ear exudate became dry and slightly decreased in amount, but local itching persisted. Etiology of ear wax hypersecretion was finally diagnosed when a narrow strip of pellagra dermal lesion was observed behind each ear and before the mastoid process. It covered just the rear groove of earhead junction on either side of the head. Nicotinamide 100mg was thereby injected daily for 3 weeks. Ear wax and pellagral dermatitis disappeared with no recurrence in the ensuing 5 years.

This case became a reminder for another patient, FU SZ 3. A housewife of 56 with diabetes, tachycardia, arrhythmia and hyperlipidemia for thiamin therapy of coronary heart disease. She had erosion of both external ear canals for 4years. As therapy progressed for four months, hypertension, tachycardia, and arrhythmia were under control, while her external ear canals became intolerable itching with drainage of liquid discharge. Nonflushing niacin $1000 \mathrm{mg}$ was given daily for 10 days and nothing troubled her again from the ears. Her coronary heart disease was then cured without abnormal blood tests.

\section{Vocal cord paralysis}

A farmer with severe lumbago, leg pain and speaking failure for 5-year [3]. Although he spoke with great effort, however, no voice or sound could be heard even very closed to the listener's ear. It exhaled only panting and no sound. After parenteral thiamin $300 \mathrm{mg}$ twice daily for 40 days, muscular pain disappeared and became very powerful. He could speak very hoarsely but clearly informative through international telephone conversation.

\section{Discussion}

\section{Nosebleed}

Nosebleed mentioned above has no immediate relation with essential hypertension although it is primarily concerned by the doctors. It must be resulted from Klesslbach's plexus malfunction, such as micro-aneurysm formation or rupture due to local or general thiamin deficiency. This notion was based on the observation of micro-aneurysm of arterioles distributed anywhere inside the body of the slaves in the labor farm. Everybody imprisoned over 5years was observed to have tiny red spots on the extremities or the trunk without local abnormal sensation and likely to be overlooked. They were few in number, no more than 10 spots in an extremity or trunk, and small in size, $1-2 \mathrm{~mm}$ in diameter. It was red and turned black within 3-5days before disappearance. When pressing with the head of a clothespin, the red spot did not disappear as seen in a liver spider. It did not rise above the surrounding skin and not swell as in insect bite. However, its color change attracted medical attention [4].

This red spot was proved to be a micro-aneurysm of an arteriole by checking the perineal side of the dilated scrotum where arterioles were visible to the naked eyes. A red berry spot could be seen crossing over the red line of an arteriole, just like a city 
crossing on the highway lines in a geographic map. It turned black within 3-5days. No local bleeding was observed during or after blackening. The distal portion of the arteriole diminished and left a dead end, which became invisible later. When the spot was freshly red it could be corrected. Prompt local subcutaneous infusing $10 \mathrm{mg}$ of thiamin $\mathrm{HCl}$ in 2 cases and $1 \mathrm{ml}$ of vitamin B complex in 1 case restored the red line. The formation of micro-aneurysm in arterioles is significant. It indicated that development of aneurysm or its rupture of larger arteries in severe malnutrition would be likely, especially in artery branching or torturing region such as subarachnoid space. "Congenital" aneurysm at the willis circle the brain of in the adult may be a superstition and surgical removal should be replaced by parenteral thiamin. This also became the theoretic basis for treatment of nose catarrh and nosebleed. The primary or secondary results of thiamin deficiency would be the excessive generation and/or accumulation of numerous detrimental metabolites, such as free radicals, $\alpha$-oxoaldehydes, advanced glycation end-products (AGEs), lipid peroxides, etc. [5]. All these metabolites interplay mutually and constitute a complicated metabolic network detrimental to the human body in different ways including Klesselbach's plexus.

\section{Rhinitis}

Rhinitis is generally considered as a result of infection and antibiotics are commonly used. However, thiamin and riboflavin injection may be more effective. Three days of parenteral thiamin $200 \mathrm{mg}$ trice daily alone had terminated the critical status in a case of fulminating viral pneumonia with high fever and thromboses of three major veins $[7,8]$. Riboflavin was observed also antibiotic but not widely used. Replacing antibiotics with thiamin and/or riboflavin in some conditions may be required or inevitable in the future.

\section{Pellagra dermatitis and hypersecretion of ear wax}

Their linkage was quite an accident finding. After extensive infection, a patient of 35 became malnourished including niacin.
In typical classic cases, 3 or 4D's (dementia, dermatitis, diarrhea, or death) should be available in pellagra. If the diagnosis were stubbornly persisted on this pattern, there would be no medical progress. Actually, pellagra could be seen in many extraordinary forms, such as massive watery diarrhea alone, skin lesions of different size and shape anywhere, and some more.

\section{Vocal cord paralysis}

It might be due to general muscle pain associate vocal fold and recurrent laryngeal nerves failure. Further correction for vocal fold was beyond the ability of the private service.

\section{Conclusion}

Parenteral thiamin is effective for nose catarrh and nosebleed. Tthiamin and riboflavin injections can cure refractory rhinitis. Excessive ear wax may be resulted from pellagra in rare cases.

\section{References}

1. Lonsdale D, Marrs C (2017) Thiamin deficiency diseases, dysautonomia, and high calorie malnutrition ( $1^{\text {st }}$ edn), In Academic Press, USA, p: 356.

2. Lee BY, Bai JH (2017) Nutritional new diseases and new concepts. KF Times Group Inc, Vancouver, Canada.

3. Ibid. New abnormalities of ariboflavinosis, pellagra, scurvy and keratomalacia, Chapter 12, pp: 153-160.

4. Ibid. Disorders of cardiovascular and respiratory systems, Chapter 7, p: 103.

5. Lee BY, Bai JH, Li Z, Wang Y (2018) Personal observation of thiamin therapy of coronary heart diseases. J J Exper Cardiol Res 4(1): 022.

6. Shangari N, Bruce WR, Poon R, O Brien PJ (2003) Toxicity of glyoxals-role of oxidative stress, metabolic detoxification and thiamine deficiency. Biochem Soc Trans 31(Pt 6): 1390-1393.

7. Lee BY, Zhou Y (2018) A letter to the editor- is parenteral thiamin a super antibiotic? Ann Nutr \& Metab 72: 149-150.

8. Lee BY, Bai JH, Li Z, Wang Y (2019) Avitaminosis fever and its clinical significance. Ann Nutri Disord \& Ther 6(1): 1-4.

For possible submissions Click below: 